\title{
In vitro screening of multidrug resistance uropathogenic Escherichia coli from the urban area of Namakkal district
}

Arjunan Gnanasekaran ${ }^{1}$, Perumal Manikandan ${ }^{1}$, Palani Poongothai ${ }^{*}$, Palani Kandasamy Senthilkumar ${ }^{{ }^{*}}$, Jagadeeshkumar Vigneshwari ${ }^{1}$

${ }^{1}$ Department of Microbiology, Faculty of Science, Annamalai University, Chidambaram, India.

${ }^{2}$ Department of Microbiology, Kandaswami Kandar's College, Paramathi Velur, India.

\begin{tabular}{l}
\hline ARTICLE INFO \\
\hline Received 21/03/2019 \\
Accepted 11/07/2019 \\
Available Online: 01/09/2019
\end{tabular}

\section{Key words:}

Multidrug resistance, uropathogenic Escherichia coli, HiCrome UTI agar, extended-spectrum beta-lactamase, hemolytic, slime, multiplex PCR.

\begin{abstract}
The aim of the study is to screen the multiple drug resistance (MDR) Uropathogenic Escherichia coli (UPEC) from the urban area of Namakkal district. To detect UPEC resistant by using different antibiotics and to analyze the virulent characteristics of UPEC and amplification of extended-spectrum beta-lactamases genes by multiplex polymerase chain reaction. Total 450 samples individually collected from the urinary tract infection (UTI) patients' and direct streaked on to the eosin methylene blue agar plates. Significant growth indicates E. coli. HiCrome UTI agar was used for rapid identification of uropathogenic E. coli. Out of 450 samples, only 62 isolates of $E$. coli were subjected to virulence characteristics, such as slime production (34\%), hemolytic activity $(56 \%)$, and beta-lactamase production (43\%). Antibiotic sensitivity test was performed with 13 different antibiotics. Among them, 62 isolates were E. coli, only five were resistant to 10 antibiotics, possess virulence characteristics. Four strains (E-12, E23, E-58, and E-97) have Temoneira, sulfhydryl variable, and cefotaxime hydrolyzing capabilities (CTX-M) antibiotic resistance genes, and E-07 have only CTX-M gene. As E. coli is the main infectious agent in patients with UTI and a potent pathogen, it was difficult to treat with routine antibiotics because day-by-day microbes are resisting to common drugs. Hence, they need alternative therapy.
\end{abstract}

\section{INTRODUCTION}

The urinary system of the human being helps maintain the proper balance of salt and water to the whole body and remove the urine from the body. It is a collection and vacuum process that includes the kidneys, ureters, bladder, and urethra. Sometimes, the urinary system has pathogenic microorganisms and colonization is known as urinary tract infection (UTI). The microorganisms are ascending cause of infection to urinary bladder and kidney. Around 150 million cases of UTIs are reported

${ }^{*}$ Corresponding Authors

Palani Poongothai, Department of Microbiology, Kandaswami Kandar College, Paramathi Velur, India.E-mail:sughiespoongothai@yahoo.in

Palani Kandasamy Senthilkumar, Department of Microbiology, Faculty of Science, Annamalai University, Chidambaram, India. E-mail:drpks1980@gmail.com every year worldwide (Källenius et al., 1981; Ohieku and Magaji, 2013). Urinary tract contamination infections are acquired in the community in all ages of females and affect an estimated 11.3 million women in the United States (Jackson et al., 2004), Asia 8.3 million per year. In India, it affected all age groups throughout life. It is recognized that women are more affected than men due to the associated short urethra and hormonal changes. UTIs that are untreated while pregnant include well-documented morbidity and mortality risks for the pregnant woman (Tajudeen et al., 2011), widespread association with catheters (Mayon-White et al., 1988), and frequent infection in outpatients (Russo and Johnson, 2003). It is due to enteric microorganisms, which are acquired from the individual gastrointestinal system. Bacteria are more prevalent and invasive. Escherichia coli, which lives regularly in the colon as a normal flora (Adeniyi et al., 2006; Jellheden et al., 1996). Not everyone who has UTI is present with symptoms but most of the patients who have at least one symptom include a frequent need to urinate, burning sensation or pain in bladder or urethra at some 
point during urination, and feel pain even when are not urinating. Often, ladies perceive uncomfortable stress in pubic bone and travel to fullness in the rectum. Urine looks milky and/or turbid, even red if the RBC is present. Usually, urinary tract infection does not cause fever if it is in the urethra or bladder, whereas it may cause fever when the infection is in kidneys. Other signs and symptoms of UTI in childhood include nausea, vomiting, and pain in the backside below the ribs.

The antibiotic is used for UTIs. More than $85 \%$ of the cases were cured with a single dose of an oral antibiotic. More complicated cases of kidney infection may require antibiotic injection or prolonged courses of oral antibiotics. Chloramphenicol, Ampicillin, Nalidixic acid, Kanamycin, Streptomycin, Nitrofurantoin, Norfloxacin, and Trimethoprim are used for the treatment of UTI. Evaluation of antibiotic resistance among the $E$. coli urinary tract isolates from outpatient clinics revealed greater resistance to these antibiotics (Zhanel et al., 2000). In most cases, repeated cycles are needed or if prophylactic long-term is needed, the prevalence of the effects of the aspects will be problematic (Sundén et al., 2006). Escherichia coli that produce extendedspectrum beta-lactamases (ESBL), which originates in patients with acquired infections in the community and in the hospital (Falagas et al., 2010). During the last decades, the increase in the number of infections caused by $E$. coli strains resistant complicates the clinical management of UTI for multiple drugs. In recent years, the incidence of cephalosporins, fluoroquinolones, and $E$. coli resistant to trimethoprim causing UTIs is of scientific importance. UTI is the second most common clinical symptom of empirical antimicrobial remediation in essential and secondary care centers (Morgan and McKenzie, 1993).

The pathogen virulent factors such as bacterial enzymes, adhesion factors such as fimbria/pili, flagellin, urease, hemolysin, metalloprotease (Fraser et al., 2002), and extended-spectrum $\beta$-lactamases (Coque et al., 2008). Although resistance to antibiotics refers to the uptake of plasmids/transposons, the significant mechanisms of resistance to antibiotics are the prevention of the accumulation of antibiotics either by minimizing uptake or by increasing the outflow, inactivating antibiotics either by hydrolysis or by modification, and qualitative alteration of the antimicrobials targets (Muratani and Matsumoto, 2004). Therefore, this study is taken to determine the risk factors related to UTI acquired in the community. Distribution of bacterial strains isolated from patients and their resistance pattern were studied. A molecular virulence feature was obtained and evaluated for a greater appreciation of resistance to multiple drugs, the potential pathogens of the UPEC. Strategic control of pathogens in a geographic area requires knowledge of the etiology of the infection; the pattern of drug resistance and the subsequent formulation of an appropriate hospital therapeutic policy to overcome the associated side effects and the increase in the cost of treatment.

\section{MATERIALS AND METHODS}

Patients for the present study were those attending at private hospitals, Paramathi-Velur, Namakkal District, Tamilnadu. The sample collection period was from June to December.

\section{Collection of sample and transport}

A total of 450 samples of mid-stream urine collected in a sterile plastic container, wide mouth and screw cap.
Approximately, 3-5 $\mathrm{ml}$ of urine samples were collected from the individual patient. Samples were accurately labeled indicating the patient's source, date, time of collection, gender, and age. Within 4-6 hours of collection, urine samples were taken to the Microbiology Laboratory in a cooler box for bacterial analysis. Urine samples are processed by macroscopic and cultural methods (Koneman et al., 1994).

\section{Macroscopy}

Visual examination of urine specimens was done. Details of samples are mentioned in the record. The color of the urine was seen on a bright background and was described as dark yellow, brown-yellow, and pinkish red. Normal urine is straw yellow.

\section{Primary isolation of uropathogenic Escherichia coli}

Plates of eosin methylene blue agar, MacConkey agar, Hektoein enteric agar, xylose lysine deoxycholate agar (XLD), and Hi-Chrome UTI agar were used. The collected urine samples were seeded directly on eosin methylene blue (EMB) agar plates and incubated for $24 \mathrm{hrs}$ at $37^{\circ} \mathrm{C}$. After incubation, the plates examined the significant growth of $E$. coli, which are colonies of greenish metallic sheen. These isolates were inoculated into the labeled plates mentioned above. Hi-Chrome agar is a differential medium recommended for early detection of microorganisms that cause UTIs. Primary identification of bacterial isolates was based on colonial aspect and pigmentation. Subcultures made on nutrient agar plates and incubated for 24 hours. Isolated organisms were recognized and confirmed by Bergey's manual of determinative bacteriology.

\section{Microscopic examination}

Simple staining, Gram staining, and Hanging drop techniques had been achieved to seem for their morphology, such as shape, Gram's nature, and motility of the isolate, respectively, among microorganisms.

\section{Assessment of virulent characteristics}

Virulent components are responsible for bacterial pathogens. The pathogen must possess aggressive, infectious, and reliable pathogenic properties. The availability of these dwellings is proportional to virulent properties. Surface factors, enzyme factor, genetic factors, and plasmid factors can exacerbate microbial virulence. Assessment of viral components will provide pathogenicity and help to take precautionary measures to look for strong pathogens. The isolated E.coli organisms were analyzed for the hemolytic activity, beta-lactamase production, slime activity followed by the below-mentioned methods $(a, b, c)$.

\section{a) Blood Agar Plate Assay}

The hemolytic activity of $E$. coli was determined by blood agar plate assay. After 24 hours of incubation, the area of hemolysis surrounding the colonies was considered to be greatest in blood agar plates containing 5\% (v/v) human blood (Brenden and Janda, 1987).

\section{b) $\beta$-Lactamase Production Assay}

The broth culture was inoculated by spots on MuellerHinton agar containing penicillin and $1 \%$ starch and incubated 
at $37^{\circ} \mathrm{C}$ overnight. The plates were then flooded with freshly prepared phosphate-buffered saline containing sodium iodide and potassium. The presence of clear colorless areas around bacterial overgrowth indicates the production of beta-lactamases. Betalactamase converts penicillin into penicilloic acid, which, with the help of starch and iodine complexion, reduces iodine to a controlled iodide (Ahmad \& Yadava, 1979).

\section{c) Slime Activity}

In the Congo red test, the medium was arranged with 37 $\mathrm{g} 1$ (50 g/l sucrose, $10 \mathrm{~g} / \mathrm{l}$ agar and $0.8 \mathrm{~g} / \mathrm{l}$ Congo red) with brain and brain infusion broth. The Congo red is used to organize into an enriched aquatic solution. The medium was autoclaved for 15 minutes at $121^{\circ} \mathrm{C}$ and separately from different components of the medium, then introduced when the agar was cooled to $45-55^{\circ} \mathrm{C}$. The plates were incubated for 24 hours at $37^{\circ} \mathrm{C}$. The resulting surface is marked by black colonies. The strains, which do not produce slime form red colonies (Freeman et al., 1989).

\section{Assessment of antibiotic sensitivity pattern}

The antibiotics susceptibility test was carried out according to the CLSI guidelines and the isolates were subjected to the antibiotic susceptibility test (Bauer et al., 1966). The susceptibility of isolates of $E$. coli to antimicrobial agents was examined by a Disk Diffusion Assay. Antibiotics used for the assay such as Co-trimoxazole (Co-30), Ciprofloxacin (CF-30), Nalidixic acid (Na-10), Ampicillin (A-10), Tetracycline (T-30), Erythromycin (E-15), Kanamycin (K-30), Bacitracin (B-10), Vancomycin (V-30), Carbenicillin (CB-100), Penicillin (P-10), Tobramycin (TB-10), and Nitrofurantoin (NF-10) $\mu \mathrm{g} /$ disk. All disks were purchased at Hi-Media, India. Mueller-Hinton Agar was used for the assay. A disk diffusion technique was followed to determine antibacterial activity. $0.5 \mathrm{McF}$ arland standard of the test culture swabbed on Mueller-Hinton agar plates (Bauer et al., 1966). Making use of the extracted template disks disbursed in the Mueller-Hinton Agar solidified with test organisms. Bacterial cultures incubated for 24 hours at $37^{\circ} \mathrm{C}$. The test performed in triplicates. The zone of inhibition was measured by using the Antibiotic zone scale (Hi-media). The patterns of resistance were interpreted according to the recommendations of the CDC. These isolates of multidrug resistance continued to use molecular characterization.

\section{Molecular characterization}

The molecular method is a useful marker for the complete characterization of Uropathogenic E. coli strains (Yamamoto, 2007; Yamamoto et al., 1995).

\section{a) Separation of plasmid DNA}

Isolation of plasmid DNA was carried out by alkaline lysis procedure with some modification. $1 \mathrm{ml}$ of an overnight culture was transferred to an Eppendorf tube (Sadasivam and Manickam, 1996). The cells were pelleted by brief centrifugation $(5,000 \mathrm{rpm})$ in the Eppendorf and supernatant was drained. The pellet was resuspended by adding $100 \mu \mathrm{l}$ of lysis buffer and the contents were mixed with the vortex. Then, $100 \mu \mathrm{l}$ of $0.1 \mathrm{M}$ Tris $\mathrm{HCl}$ was added and mixed well by inverting the content (4-5 times). To the above viscous content, $100 \mu \mathrm{l}$ of buffer was added and the content was inverted 4-5 times to mix most of genomic DNA, and other cellular debris will precipitate in a viscous group. It centrifuged at 12,000 rpm and clump removed. The clear lysate (supernatant) was transferred to another Eppendorf tube. $150 \mu \mathrm{l}$ of $100 \%$ Isopropanol was added, mixed well, and the contents were centrifuged at 12,000 rpm for 30 minutes. The supernatant drained; In addition, $150 \mu \mathrm{l}$ of absolute alcohol was added and centrifuged at 10,000 rpm for 20 minutes. The supernatant was drained and the DNA pellets were dissolved with $20 \mu \mathrm{l}$ TE buffer. The extracted plasmid DNA was confirmed by running of agarose gel electrophoresis.

\section{b) Polymerase chain reaction for amplification of ESBL genes}

All sequences of partial or total resistance genes available from the resistance gene were determined according to the protocol with some modification (Maya et al., 2011). The primers were obtained from Sigma, India, and were used in the polymerase chain reaction (PCR) comprised Primer. PCR mixture was prepared in a thin-walled PCR tube in a sterile laminar flow hood. Add the following reagents as follows. Each PCR reaction mixture $(20 \mu \mathrm{l})$ contained $2 \mu \mathrm{l}$ of template DNA (plasmid DNA), $2 \mu \mathrm{l}$ of 10X PCR buffer, $0.5 \mu \mathrm{l}$ of $(0.5 \mu \mathrm{M})$ each of the primers, 1 $\mu \mathrm{l}$ of $0.2 \mathrm{mM}$ of each deoxynucleotide triphosphate, and $1 \mu \mathrm{l}$ of Taq DNA polymerase (Con $5 \mathrm{U} / \mu \mathrm{l})$ and $8.0 \mu \mathrm{l}$ of molecular grade water. A short spin was given to establish the materials that the tubes kept in a thermocycler (Genei). After initial denaturation at $95^{\circ} \mathrm{C}$ for $15 \mathrm{~min}$, the samples were subjected to 30 cycles of denaturation at $94^{\circ} \mathrm{C}$ for $30 \mathrm{sec}$, annealing at $62^{\circ} \mathrm{C}$ for 1.30 minutes and extended at $72^{\circ} \mathrm{C}$ for 1 minute. A remaining extension was performed at $72^{\circ} \mathrm{C}$ for 10 minutes. Following PCR, aliquots (20 $\mu \mathrm{l})$ of the response mixtures were analyzed by electrophoresis on a $1.5 \%$ Agarose gel, containing ethidium bromide $(0.2 \mathrm{mg} / \mathrm{ml})$, in the presence of a gorgeous DNA molecular weight marker. Then observe the amplification bands below the UV Transilluminator and detection of resistance gene with the use of the marker.

\section{RESULTS AND DISCUSSION}

Urinary tract infections are the most frequent bacterial infection. The UTI is responsible for the huge morbidity and high costs of medical illnesses around the world (Kudinha et al., 2012). A total of 450 urine samples were collected from male and female patients with UTI during the study period. $65 \%(n=292)$ of urine samples were from females and $35 \%(n=158)$ were from males. The top UTI women with this study are largely supported by different writers around the world. In Belgian peoples affected that $63 \%$ of UTI cases were women and $37 \%$ were men (Ismaili et al., 2011), common problem in primary health care (Mwaka et al., 2011). In India, most UTI was assessed using urine in the middle of the stream. It is a simple and easy method and it refers to the true state of the infection of the system (Acharya et al., 2011).

Generally, females have shortness of urethra in the urinary tract, which is 1.5 inches compared to 8 inches in males. Bacteria from fecal matter depend on anal opening and may turn into urinary tract opening without complications. Frequent sexual commitment is the most essential threat feature for urinary tract infection in young women. Almost $80 \%$ of postmenopausal women have UTIs that appear within 24 hours after intercourse. Early in pregnancy, common urination is the most common 
symptom of UTI, mainly due to pressure on the bladder. Women are at increased risk for UTI after menopause. This is mainly caused by the loss of estrogen, which slows down the walls of the urinary tract and reduces its ability to resist bacteria. Loss of estrogen can reduce certain immune factors in the vagina, which can help prevent $E$. coli from joining the vaginal cells. Women who have skin pores and hypersensitive reactions to substances such as soaps, vaginal creams, bubble baths, or other chemicals used in the genital area are at a multiple risk for UTIs. In such cases, hypersensitivity reactions can also cause small lesions that can introduce bacteria. Age distribution of aggregated urine samples between the target group is shown in Figure 1.

The most variety of urine samples amassed from the age group 41-50 years. In all age groups, females have been at the top. This study confirmed that the occurrence of UTI was high among female than the male of different age groups. The female UTI incidences were high in all age groups. A slight variation noted with the age above 50 as only less number of female sample was collected during the study period (Sharma et al., 2007). Collected urine samples were visually examined the color. The maximum number of urine samples collected from UTI cases was brownishyellow $(n=298) ; 66 \%$, followed by dark yellow $(n=89) ; 20 \%$, dna pinkish-red in color $(n=63) ; 14 \%$.

Generally, the color of the urine samples depends on the inflammatory and pathological conditions associated with the urinary tract. Cystitis and pyelonephritis are major inflammatory diseases caused by bacterial infections. Brownish-yellow and pinkish-red color of the urine was due to the inflammatory response. Identification of pure isolates of $E$. coli was carried out using the standard bacteriologic method. EMB agar, MacConkey Agar, XLD agar, Hektoein Enteric agar, and Hi-Chrome UTI agar were used for the selective cum differential isolation of Uropathogenic E. coli (Fig. 2, Table 1).

It produced specific colonies on these media. All the viable microorganisms were identified by biochemical experiments through the development of selective and differential media. Identification of $E$. coli in terms of stable culture and biochemical properties was also supported (Fig. 3) (Daoud and Afif, 2011).

The bacterial etiology of UTIs is properly established, Escherichia coli being the predominant pathogen (Daza et al.,

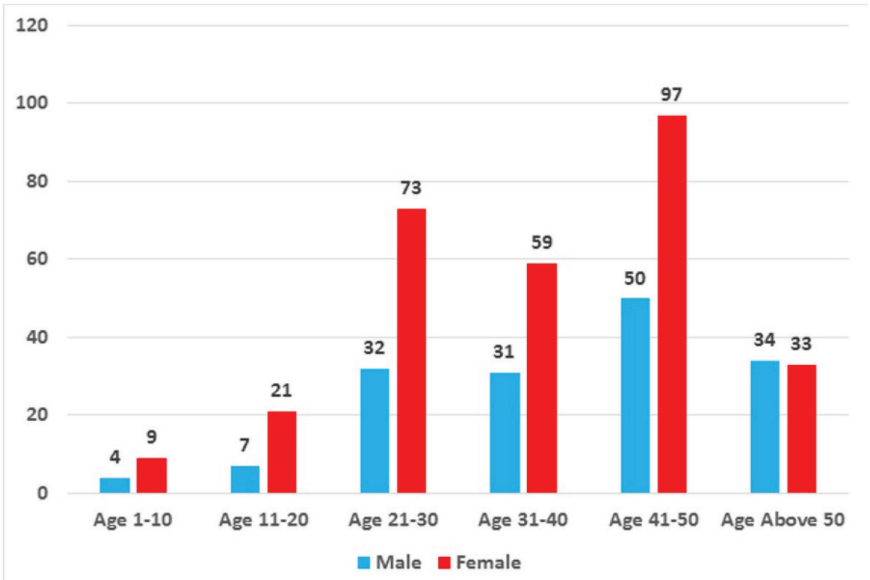

Figure 1. Age-wise distribution of UTI among the study population.
2001; Hooton, 1991; Raz et al., 2000; Zhanel et al., 2006). In this study, a total of 105 E.coli was recovered from 450 of urine sample. Sixty two E. coli were isolated as a pure isolate and 43 isolates were isolated as mixed isolates. Age-wise analysis, that the higher incidences of $E$. coli were noted in the age group 21-30 followed by the 31-40 age group. Lowest incidence noted among 1-10 age group followed by 11-20 (Fig. 4).

Out of the six types of age groups, females showed the highest prevalence in $21-30$ age groups $(n=14)$. Male showed the highest prevalence in $31-40$ age groups $(n=11)$. The higher rate of $E$. coli was recovered from the female urine samples $(68 \%$;

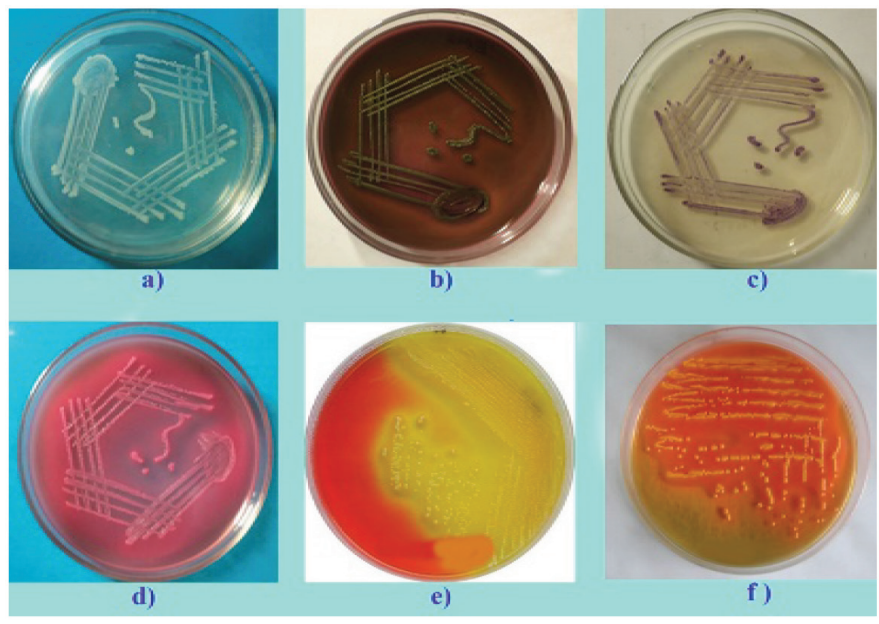

Figure 2. Growth characteristics of Uropathogenic Escherichia coli on Different media. (a) Nutrient agar, (b) EMB agar, (c) HiCrome UTI agar, (d) MacConkey agar, (e) XLD agar and (f) Hektoen enteric Agar.

Table 1. Growth characteristics of uropathogenic E. coli on different media.

\begin{tabular}{cll}
\hline S. No. & Media & Growth Pattern \\
\hline 1 & Nutrient Agar & Small, circular, entire colony \\
2 & EMB Agar & Greenish Metallic sheen colonies \\
3 & HiCrome UTI Agar & Pinkish Purple color colonies \\
4 & Mac Conkey Agar & Lactose Fermenting pink colonies \\
5 & XLD Agar & Yellow color colonies \\
6 & Hektoen enteric Agar & Salmon color colonies \\
\hline
\end{tabular}

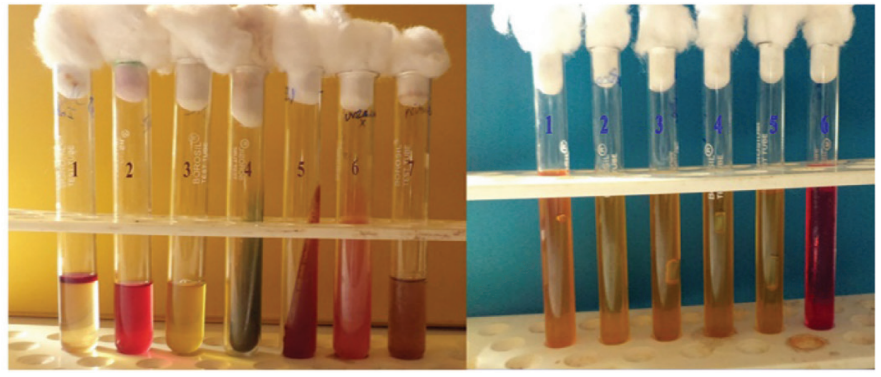

Figure 3. Escherichia coli biochemical features: (a) 1. Indole +ve, 2. Methyl Red +ve, 3. Voges Proskauer -Ve, 4. Citrate -ve, 5. TSI -A/A Gas +ve, 6. Urease, 7. Nitrate, (b) Carbohydrates fermentation 1. Glucose-AG, 2. Sucrose-A, 3. Maltose-AG, 4. Lactose-AG, 5. Xylose-AG, 6. Sorbitol-Negative, A-Acid, AG-Acid and Gas. 
$n=42$ ), whereas male patients derived specimens showed only $(32 \% ; n=20)$. The present study revealed $E$. coli as the major pathogen of UTI - supported different authors in different research from different countries (Chlabicz et al., 2011; Gower and Wardener 1971; Sharma et al., 2011; Siedelman et al., 2012; Walters et al., 2012; Yamamichi et al., 2012). In the present study, 62 pure isolates of $E$. coli selected for further characterization.

\section{Assessment of virulent factors}

The production of slime, $\beta$-lactamase, and hemolytic activity is the major virulence determinant of uropathogens. Sixty two isolates of $E$. coli from the study were subjected to virulence factor determination and showed the presence of one of the tested

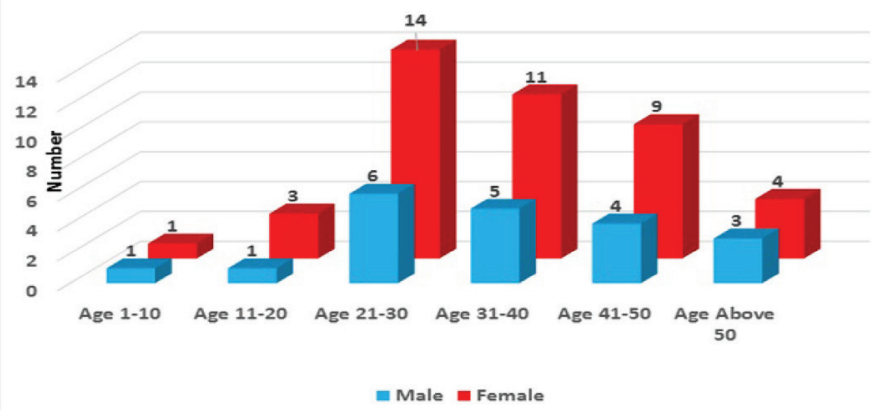

Figure 4. Age-wise distribution of E. coli positive among male and female.

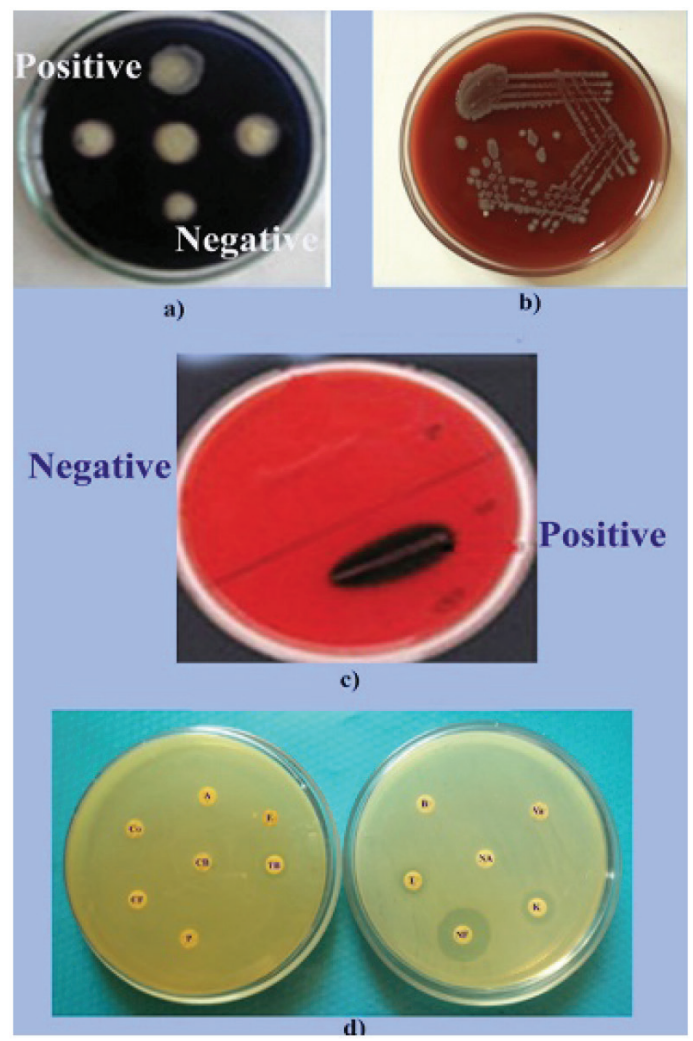

Figure 5. Escherichia coli with their virulent factors: (a) Beta-lactamase, (b) Hemolysis, (c) Slime activity, and (d) Antibiogram. virulent factors. Of those tested, E. coli isolation showed $34 \%$ production of slime factors, $43 \%$ had $\beta$-lactamase activity, and $56 \%$ of the strains represented hemolytic activity (Fig. 5). UPEC has been exposed to a number of virulence factors and helps colonize E. coli in the bladder. 27 (35.1\%) and 50 (64.9\%) ESBLs produce neonates and UPEC strains, respectively (Hilbert et al., 2012). This study has led to a less similar finding and can highlight that many environmental conditions play an important role in the expression of the respective gene product that determines the virulence.

\section{Antibiotic susceptibility assay}

Antibiotic susceptibility testing of E. coli isolates was carried out according to the Kirby \& Bauer disk diffusion method. All confirmed E. coli isolates with 62 cultures were tested for antimicrobial susceptibility and were noted to be resistant to a minimum of 10 various groups of antibiotics $(77 \%)$ out of 13 antibiotics added in the study. Only $23 \%(n=4)$ of the isolates are sensitive to all antibiotics tested. This indicates that all isolates are resistant to several levels of antibiotics. Against the aminoglycoside-gentamycin, $32 \%$ of the isolates were sensitive which was in accordance (Zaman et al., 2006). 76.5\% of community-acquired infections were due to E. coli and $60.6 \%$ of which were E. coli ESBL producers. (Siedelman et al., 2012; Walters et al., 2012).

Percentage of resistance patterns of E.coli of the study were found to be $100 \%$ for Ciprofloxacin (CF), Ampicillin (A), Carbenicillin (CB), Tetracycline (T), Co-trimoxazole (Co), 98\% for Erythromycin (E) and Bacitracin (B), 93\% for Penicillin (P), 91\% for Nalidixic acid (Na), and 89\% for Vancomycin (V). Additionally, most sensitivity rates were reported for Nitrofurantoin (NF) (100\%), followed by Tobramycin $(90 \%)$ and Kanamycin (62\%) (Table.2). The present evaluation has brought out the current antibiotic and antimicrobial resistance of many antibiotics that have registered a dangerous situation. Therefore, it is becoming relevant to the new antimicrobial treatment developed with fewer side effects, such as the urinary tract leading to chronic infection in the bladder and kidney and effective treatment to reduce stress in the human mind. This problem is for the short term. Severe implications for

Table 2. Antibiotic sensitivity patterns of uropathogenic E. coli.

\begin{tabular}{clcc}
\hline S. No. & Antibiotics & Resistant (\%) & Sensitive (\%) \\
\hline 1 & Carbenicillin (CB) & 100 & 00 \\
2 & Ciprofloxacin (CF) & 100 & 00 \\
3 & Ampicillin (A) & 100 & 00 \\
4 & Erythromycin (E) & 98 & 02 \\
5 & Co-trimoxazole (Co) & 100 & 00 \\
6 & Nalidixic acid (Na) & 91 & 09 \\
7 & Tetracycline (T) & 100 & 00 \\
8 & Kanamycin (K) & 38 & 62 \\
9 & Bacitracin (B) & 98 & 02 \\
10 & Vancomycin (Va) & 89 & 11 \\
11 & Penicillin (P) & 93 & 07 \\
12 & Nitrofurantoin (NF) & 00 & 100 \\
13 & Tobramycin (TB) & 10 & 90 \\
\hline
\end{tabular}


prescribing antibiotics for urinary and bladder infections in the community and hospitalization for bacterial infections (Melzer and Petersen, 2007). Nitrofurantoin has been used successfully in the remedy of urinary-tract infection for 20 years (Gower and Wardener, 1971).

\section{Molecular characterization of $E$. coli}

Molecular methods are useful markers for the complete characterization of Uropathogenic E. coli strains (Yamamoto et al., 2007). Out of 62 isolates, 5 isolates were completely resistant to all the antibiotics and all these strains were showed hemolytic activity, $\beta$ lactamase production, and slime production (Table 2 ). Based on the resistance pattern of Uropathogenic E. coli, chemical virulence factors (hemolytic activity, $\beta$ lactamase production, and slime production), five UPEC were selected for plasmid-mediated antibiotic resistance and were analyzed for these organisms (Fig. 6, Table 3).

\section{Plasmid-mediated antibiotic resistance isolates by PCR}

The five multi-drug resistant isolates displayed notable results when their antibiotic resistance genotypes analyzed by multiplex PCR with cefotaxime hydrolyzing capabilities (CTX-M), Temoneira (TEM), and sulfhydryl variable (SHV) gene primers. The test isolates were identified to carry three antibiotic resistance genotypes. One strain showed only one resistance gene CTX-M. Other four strains possessed TEM, SHV, and CTX-M genes (Fig. 6). TEM gene was detected in $28 \%$ of the isolates, SHV gene in $69.5 \%$, and CTX-m gene was detected in only $2.5 \%$ isolate. TEM and SHV simultaneously detected in $25 \%$ of isolates. Based on their findings, it concluded that strict infection control measures

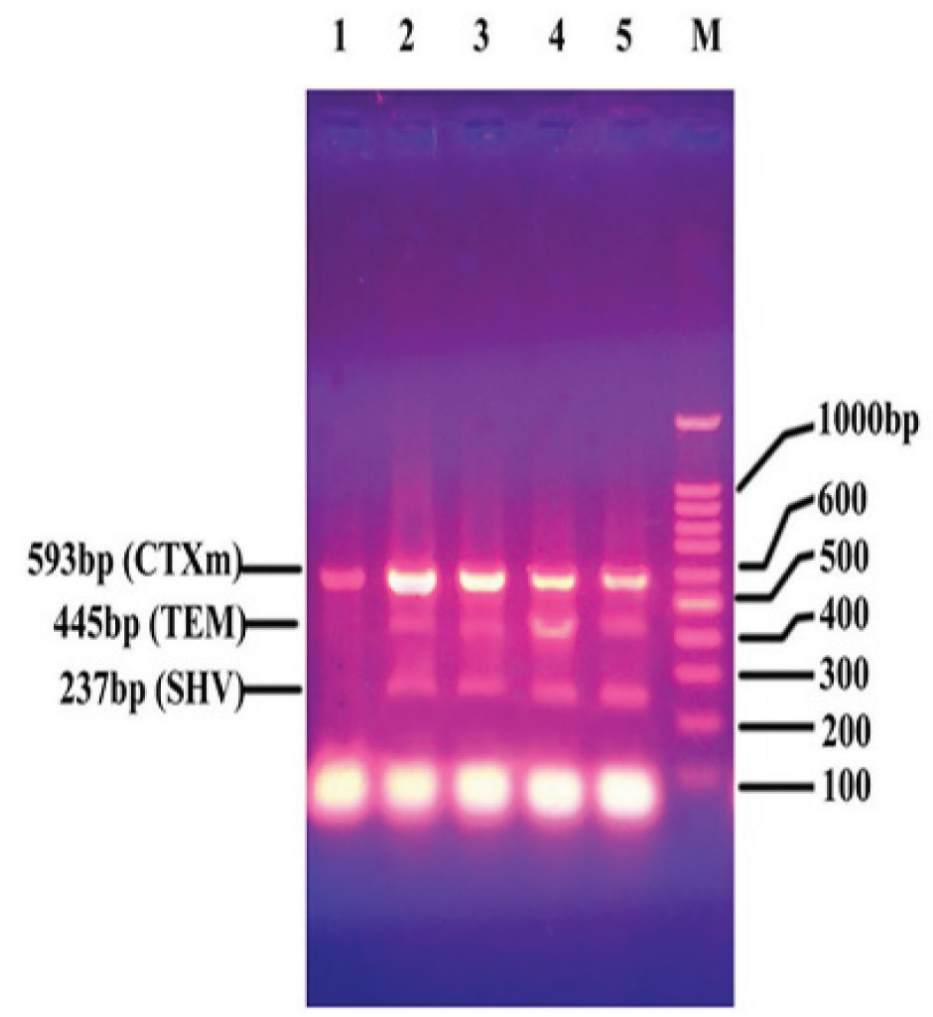

Figure 6. ESBL genes 1-E07, 2 -E12, 3- E23, 4 - E58, 5- E97, M- Marker, E- E. coli.

Table 3. Selection of UPEC for molecular characterization.

\begin{tabular}{|c|c|c|c|c|c|c|c|c|c|c|c|c|c|c|}
\hline \multirow[b]{2}{*}{ S. No } & \multirow[b]{2}{*}{ StrainNo. } & \multicolumn{3}{|c|}{ Virulence } & \multicolumn{10}{|c|}{ Antibiotic sensitivity } \\
\hline & & $\stackrel{\overrightarrow{0}}{\bar{\sigma}}$ & $\stackrel{\mathscr{E}}{\stackrel{\Xi}{\circ}}$ & 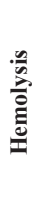 & 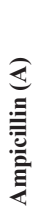 & 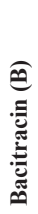 & 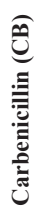 & 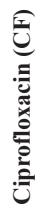 & 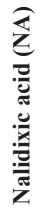 & 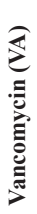 & 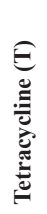 & 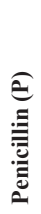 & 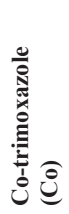 & 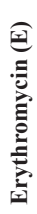 \\
\hline 1 & E-07 & + & + & + & $\mathrm{R}$ & $\mathrm{R}$ & $\mathrm{R}$ & $\mathrm{R}$ & $\mathrm{R}$ & $\mathrm{R}$ & $\mathrm{R}$ & $\mathrm{R}$ & $\mathrm{R}$ & $\mathrm{R}$ \\
\hline 2 & E-12 & + & + & + & $\mathrm{R}$ & $\mathrm{R}$ & $\mathrm{R}$ & $\mathrm{R}$ & $\mathrm{R}$ & $\mathrm{R}$ & $\mathrm{R}$ & $\mathrm{R}$ & $\mathrm{R}$ & $\mathrm{R}$ \\
\hline 3 & E-23 & + & + & + & $\mathrm{R}$ & $\mathrm{R}$ & $\mathrm{R}$ & $\mathrm{R}$ & $\mathrm{R}$ & $\mathrm{R}$ & $\mathrm{R}$ & $\mathrm{R}$ & $\mathrm{R}$ & $\mathrm{R}$ \\
\hline 4 & E-58 & + & + & + & $\mathrm{R}$ & $\mathrm{R}$ & $\mathrm{R}$ & $\mathrm{R}$ & $\mathrm{R}$ & $\mathrm{R}$ & $\mathrm{R}$ & $\mathrm{R}$ & $\mathrm{R}$ & $\mathrm{R}$ \\
\hline 5 & E-97 & + & + & + & $\mathrm{R}$ & $\mathrm{R}$ & $\mathrm{R}$ & $\mathrm{R}$ & $\mathrm{R}$ & $\mathrm{R}$ & $\mathrm{R}$ & $\mathrm{R}$ & $\mathrm{R}$ & $\mathrm{R}$ \\
\hline
\end{tabular}


should be used and hospitalized broad-spectrum cephalosporin drugs (Petrove et al., 2007). The presence of CTX-M type extended the spectrum of beta-lactamases reported among pathogens from different parts of the world. The CTX-M was a significant reason for antibiotic resistance as reported (Lepeule et al., 2012). The study found that all the isolates belonged to ESBL types predictably leading to complications in therapy. It also indicated that the increased prevalence of MDR-UPEC pathogens complicated the treatment of UTI (Molina-López et al., 2011).

\section{CONCLUSION}

UTI prevention is always the goal of doctors. There are many proven and unproven strategies to accomplish this task. Most UTIs disappear spontaneously if left untreated, but symptoms can persist for a long time (Buonanno et al., 2006). In this study concluded that $E$. coli is one of the most predominant pathogens of UTI infection in patients of Paramathi Velur, Namakkal district, Tamil Nadu, India. E. coli possess multiple virulent factors and were MDR-ESBL pathogens, which are difficult to treat. The emergence of Multidrug resistance uropathogens is very difficult to treat.

\section{ACKNOWLEDGMENT}

The authors express their gratitude to all the staffs of the Department of Microbiology, Kandaswami Kandar's College, Periyar University.

\section{CONFLICTS OF INTEREST}

The authors declare no conflicts of interest in the study.

\section{FUNDING SOURCE}

None.

\section{REFERENCES}

Adeniyi BA, Ayeni FA, Ogunbanwo ST. Antagonistic activities of lactic acid bacteria isolated from Nigerian fermented dairy food against organisms implicated in urinary tract infection. Biotechnology, 2006; 5(2):183-8; doi:10.3923/biotech.2006.183.188

Acharya A, Gautam R, Subedee L. Uropathogens and their antimicrobial susceptibility pattern in Bharatpur, Nepal. Nepal Med Coll J, $2011 ; 13(1): 30-3$

Ahmad S, Yadava JNS. Rapid detection of $\beta$-lactam antibiotic resistance among clinical isolates of Escherichia coli. Indian Vet Med J, $1979 ; 3: 256-9$

Bauer AW, Kirby WM, Sherris JC, Turck M. Antibiotic susceptibility testing by a standardized single disk method. Am J Clin Pathol, 1966; 45(4):493-6; doi:10.1093/ajcp/45.4 ts.493

Brenden R, Janda JM. Detection, quantitation and stability of the beta haemolysin of Aeromonas spp. J Med Microbiol, 1987; 24(3):247-51; doi:10.1099/00222615-24-3-247

Buonanno Jr. AP, Damweber BJ. Review of urinary tract infection. US Pharm, 2006; 6:HS-26-36.

Chlabicz S, Leszczynska K, Lukas W, Gualco L, Schito G, Naber KG. Uncomplicated lower urinary tract infections in femalesclinical aspects, aetiology and antimicrobial resistance epidemiology. Results of the ARESC (Antimicrobial Resistance Epidemiological Survey on Cystitis) study in Poland and their implications for empiric therapy. Przegl Epidemiol, 2011; 65(2):345-51. Available via http://europepmc.org/ abstract/MED/21913487

Coque TM, Novais A, Carattoli A, Poirel L, Pitout J, Peixe L, Baquero F, Cantón R, Nordmann P. Dissemination of clonally related E. coli strains expressing ESBL CTX-M-15. Emerg Infect Dis, 2008; 14(14):195-200; doi:10.3201/eid1402.070350

Daoud Z, Afif C. Escherichia coli isolated from urinary tract infections of Lebanese patients between 2000 and 2009: epidemiology and profiles of resistance. Chemother Res Pract, 2011; 2011:1-6; doi:10.1155/2011/218431

Daza R, Gutierrez J, Piedrola G. Antibiotic susceptibility of bacterial strains isolated from patients with community- acquired urinary tract infections. Int J Antimicrob Agents, 2001; 18:211-5; doi:10.1016/ S0924-8579(01)00389-2

Falagas ME, Kastoris AC, Kapaskelis AM, Karageorgopoulos DE. Fosfomycin for the treatment of multidrug-resistant, including extended-spectrum $\beta$-lactamase producing, Enterobacteriaceae infections: a systematic review. Lancet Infect Dis, 2010; 10(1):43-50; doi:10.1016 S1473-3099(09)70325-1

Fraser GM, Claret L, Furness R, Gupta S, Hughes C. Swarmingcoupled expression of the Proteus mirabilis hpmBA haemolysin operon. Microbiology, 2002; 148(7):2191-201.

Freeman DJ, Falkiner FR, Patrick S. New method for detecting slime production by coagulase negative staphylococci. J Clin Pathol, 1989; 42:872-4.

Gower PE, Wardener HEDE. Prevention of urinarytract infection with low-dose nitrofurantoin. Lancet, 1971; 20: $1112-4$.

Hilbert DW, Paulish-Miller TE, Tan CK, Carey AJ, Ulett GC, Mordechai E, Adelson ME, Gygax SE, Trama JP. Clinical Escherichia coli isolates utilize alpha-hemolysin to inhibit in vitro epithelial cytokine production. Microbes Infect, 2012; 14(7-8):628-38; doi:10.1016/j. micinf.2012.01.010

Hooton TM, Stam WE. Management of acute uncomplicated urinary tract infection in adults. Med Clin North Am, 1991; 75(2):339-57. Available via http://europepmc.org/abstract/MED/1996038

Ismaili $\mathrm{K}$, Wissing $\mathrm{KM}$, Lolin $\mathrm{K}$, Le PQ, Christophe $\mathrm{C}$, Lepage P, Hall M. Characteristics of first urinary tract infection with fever in children. Pediatr Infect Dis J, 2011; 30(5):371-4; doi:10.1097/ INF.0b013e318204dcf3

Jackson SL, Boyko EJ, Scholes D, Abraham L, Gupta K, Fihn SD. Predictors of urinary tract infection after menopause: a prospective study Am J Med, 2004; 117(12):903-11; doi:10.1016/j.amjmed.2004.07.045

Jellheden B, Norrby RS, Sandberg T. Symptomatic urinary tract infection in women in primary health care: bacteriological, clinical and diagnostic aspects in relation to host response to infection. Scand J Prim Health Care, 1996; 14(2):122-8; doi:10.3109/02813439608997082

Källenius G, Svenson SB, Hultberg H, Möllby R, Svenson SB, Helin I, Hultberg H, Cedergren B, Winberg J. Occurrence of P-Fimbriated Escherichia coli in urinary tract infections. Lancet, 1981; 318(82608261):1369-72; doi:10.1016/S0140-6736(81)92797-5

Koneman EW, William MJ, Stephen DA, Schreeken B. Laboratory and clinical diagnosis of infections diseases. In: Introduction to diagnostic Microbiology. JB Lippincott Company, 1 Philadelphia, pp 1-19, 1994.

Kudinha T, Kong F, Johnson JR, Andrew SD, Anderson P, Gilbert G. Multiplex PCR-based reverse line blot assay for simultaneous detection of 22 virulence genes in uropathogenic Escherichia coli. Appl Env Microbiol, 2012; 78(4):1198-202.

Lateef A, Gueguim-Kana EB, Oloke J. Antimicrobial resistance of bacterial strains isolated from orange juice products. Afr J Biotechnol, 2004; 3(June):334-8

Lepeule R, Ruppé E, Le P, Massias L, Chau F, Nucci A, Lefort A, Fantin B. Cefoxitin as an alternative to carbapenems in a murine model of urinary tract infection due to Escherichia coli harboring CTX-M-15type extended-spectrum $\beta$-lactamase. Antimicrob Agents Chemother, 2012; 56(3):1376-81; doi:10.1128/AAC.06233-11

Maya AS, Kesani P, Hanna LE, Sarayu YL. Phenotypic and genotypic characterization of extended spectrum beta -lactamase producing Escherichia coli clinical isolates from semiurban area. J Pharm Res, 2011; 4(1):6-10.

Mayon-White RT, Ducel G, Kereselidze TTE, Mayon-White RT, Ducel G, Kereselidze T, Tikomirov E. An international survey of the prevalence of hospital-acquired infection. J Hosp Infect, 1988; 11 Suppl A(8):43-8; doi:10.1016/0195-6701(88)90164-8

Melzer M, Petersen I. Mortality following bacteraemic infection caused by extended spectrum beta-lactamase (ESBL) producing E. coli 
compared to non-ESBL producing E. coli. J Infect, 2007; 55(3):254-9; doi:10.1016/j.jinf.2007.04.007

Molina-López J, Aparicio-Ozores G, Ribas-Aparicio RM, et al. Drug resistance, serotypes, and phylogenetic groups among uropathogenic Escherichia coli including O25-ST131 in Mexico City. J Infect Dev Ctries, 2011; 5(12):840-9; doi:10.3855/jidc.1703

Morgan MG, McKenzie H. Controversies in the laboratory diagnosis of community-acquired urinary tract infection. Eur J Clin Microbiol Infect Dis, 1993; 12(7):491-504; doi:10.1007/BF01970954

Muratani T, Matsumoto T. Bacterial resistance to antimicrobials in urinary isolates. Int J Antimicrob Agents, 2004; 24(Suppl 1):28-31; doi:10.1016/j.ijantimicag.2004.02.001

Mwaka AD, Mayanja-Kizza H, Kigonya E, Kaddu-Mulindwa $\mathrm{D}$, Member-secretary T. Bacteriuria among adult non-pregnant women attending Mulago hospital assessment centre in Uganda. Afr Health Sci, 2011; 11(2):182-9.

Ohieku JD, Magaji RA. Urinary tract infections caused by Pseudomonas, Klebsiella and Proteus species: a 2005-2009 survey of trends in their infectivities and susceptibilities to selected fluoroquinolones in a tertiary hospital in Nigeria. World J Pharm Res, 2013; 2(5):1238-53.

Petrove V, Mayer D, Šlaus M, Strinovi D, Škavi J. Characterization of the extended-spectrum $\beta$-lactamases and determination of the virulence factors of uropathogenic Escherichia coli strains isolated from children. Wiener Klinische Wochenschrift, 2007; 52.

Raz R, Schiller D, Nicolle LE. Chronic indwelling catheter replacement before antimicrobial therapy for symptomatic urinary tract infection. J Urol, 2000; 164(4):1254-8; doi:10.1016/S0022-5347(05)67150-9

Russo TA, Johnson JR. Medical and economic impact of extraintestinal infections due to Escherichia coli: focus on an increasingly important endemic problem. Microbes Infect, 2003; 5(5):449-56; doi:10.1016/S1286-4579(03)00049-2

Sadasivam S, Manickam A. Biochemical methods. 2nd edition, New Age International (P) Limited Publishers, New Delhi, India, 2004

Sharma S, Bhat GK, Shenoy S. Virulence factors and drug resistance in Escherichia coli isolated from extraintestinal infections. Indian J Med Microbiol, 2007; 132(4):53-5.

Sharma A, Shrestha S, Upadhyay S, Rijal P. Clinical and bacteriological profile of urinary tract infection in children at Nepal Medical College Teaching Hospital. Nepal Med Coll J, 2011; 13(1):24-6. Available via http://www.ncbi.nlm.nih.gov/pubmed/21991696.

Siedelman L, Kline S, Duval S. American Journal of Infection Control Risk factors for community- and health facility e acquired extendedspectrum $b$-lactamase e producing bacterial infections in patients at the University of Minnesota Medical Center, Fairview. Am J Infect Control, 2012; 40(9):849-53; doi:10.1016/j.ajic.2011.10.019

Sundén F, Håkansson L, Ljunggren E, Wullt B. Bacterial interference-is deliberate colonization with Escherichia coli 83972 an alternative treatment for patients with recurrent urinary tract infection? Int J Antimicrob Agents, 2006; 28(Suppl 1):26-9; doi:10.1016/j.ijantimicag.2006.05.007

Tajudeen B, Bolanle A, Samuel T O, Stella S, Emmanuel O. Antibacterial activities of lactic acid bacteria isolated from selected vegetables grown in Nigeria: a preliminary report. Sierra Leone J Biomed Res, 2011; 3(3): 128-32.

Walters MS, Lane MC, Vigil PD, Smith SN, Walk ST, Mobley HLT. Kinetics of uropathogenic Escherichia coli metapopulation movement during urinary tract infection. MBio, 2012; 3(1):1-11; doi:10.1128/mBio.00303-11.Editor

Yamamichi F, Shigemura K, Matsumoto M, Nakano Y, Arakawa SFM. Relationship between urinary tract infection categorization and pathogens' antimicrobial susceptibilities. Urol Int, 2012; 88:198-208; doi:10.1159/000334976

Yamamoto S. Molecular epidemiology of uropathogenic Escherichia coli. J Infect Chemother, 2007; 13(2):68-73; doi:10.1007/s10156-007-0506-y

Yamamoto S, Tsukamoto T, Kurazono $\mathrm{H}$, Takeda Y YO. Distribution of virulence factors in Escherichia coli isolated from urine of cystitis patient. Microbiol Immunol, 1995; 39(6):401-4.

Zaman MS, Khan AU, Zaman MS, Unit IB. Multiple drug resistance pattern in Urinary Tract Infection patients in Aligarh. Biomed Res, 2006; 17(3):179-81.

Zhanel GG, Hisanaga TL, Laing NM, DeCorby MR, Nichol KA, Palatnik LP, Johnson J, Noreddin A, Harding GK, Nicolle LE, Hoban DJ; NAUTICA Group. Antibiotic resistance in Escherichia coli outpatient urinary isolates: final results from the North American Urinary Tract Infection Collaborative Alliance (NAUTICA). Int J Antimicrob Agents, 2006; 27(6):468-75; doi:10.1016/j.ijantimicag.2006.02.009

Zhanel GG, Karlowsky J a, Godfrey KM, et al. a canadian national surveillance study of urinary tract isolates from outpatients: comparison of the activities of ciprofloxacin a canadian national surveillance study of urinary tract isolates from outpatients : comparison of the activities of trimethop. Antimicrob Agents Chemother, 2000; 44(4):1089-92; doi:10.1128/AAC.44.4.1089-1092.2000.Updated

How to cite this article:

Poongothai P, Gnanasekaran A, Manikandan P, Senthilkumar

PK, Vigneshwari J. In vitro screening of multidrug resistance uropathogenic Escherichia coli from the urban area of Namakkal district. J Appl Pharm Sci, 2019; 9(09):084-091. 